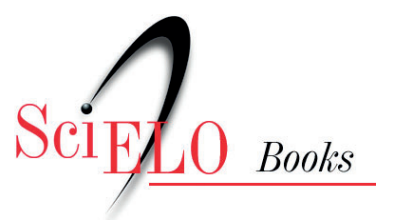

\title{
10. A cultura escolar da/na EJA - contributos para compreender e repensar as ações cotidianas dos professores
}

\author{
Marinaide Freitas \\ Paulo Marinho
}

\section{SciELO Books / SciELO Livros / SciELO Libros}

FREITAS, M., and MARINHO, P. A cultura escolar da/na EJA - contributos para compreender e repensar as ações cotidianas dos professores. In: PAIVA, J., comp. Aprendizados ao longo da vida: sujeitos, políticas e processos educativos [online]. Rio de Janeiro: EDUERJ, 2019, pp. 205-219. Pesquisa em educação/Educação ao longo da vida series. ISBN: 978-65-990364-9-1. https://doi.org/10.7476/9786599036491.0011.

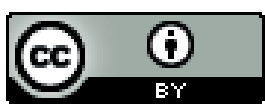

All the contents of this work, except where otherwise noted, is licensed under a Creative Commons Attribution 4.0 International license.

Todo o conteúdo deste trabalho, exceto quando houver ressalva, é publicado sob a licença Creative Commons Atribição $\underline{4.0}$.

Todo el contenido de esta obra, excepto donde se indique lo contrario, está bajo licencia de la licencia $\underline{\text { Creative Commons }}$ Reconocimento 4.0. 


\title{
10
}

\section{A cultura escolar da/na EJA - contributos para compreender e repensar as ações cotidianas dos professores}

\author{
Marinaide Freitas \\ Paulo Marinho
}

\section{Introdução}

Este artigo tem por base o nosso envolvimento no Programa Nacional de Cooperação Acadêmica (PROCAD/Casadinho 2012-2017), financiado pelo CNPq/Capes/Inep, tendo como eixos temáticos: Educação Continuada, Currículo e Práticas Culturais, no âmbito do Núcleo de Estudos, Pesquisa e Extensão sobre Alfabetização (Nepeal) do Centro de Educação (Cedu) da Universidade Federal de Alagoas (Ufal), envolvendo três instituiçóes públicas de ensino superior: Universidade Federal de Alagoas (UFAL), Universidade do Estado do Rio de Janeiro (UERJ - Associada I) e Universidade Federal do Rio Grande do Norte (UFRN - Associada II). 
Insere-se nos estudos realizados no eixo culturas que foram articulados às orientaçóes de trabalhos de conclusão de curso (TCC), no caso específico, a Licenciatura em Pedagogia; de dissertaçóes, teses concluídas e em andamento, na Pós-Graduação em Educação Brasileira (PPGE/UFAL); além de pesquisas de Iniciação Científica (IC/Pibic, 2015-2016, 2016-2017 e 2017-2018); e do estágio de Pós-doutorado em Educação (Capes, 2015-2020), sendo este último com a temática sobre culturas organizacionais escolares e profissionais docentes, em intercâmbio com o Centro de Investigação e Intervenção Educativas (CIIE) da Faculdade de Psicologia e de Ciências da Educação da Universidade do Porto (FPCE-UP). Concomitantemente, dialoga com o estudo também ainda em desenvolvimento, financiado pela Fundação de Amparo à Pesquisa do Estado de Alagoas (FAPEAL, 2017-2018), focalizado, essencialmente, na cultura escolar da/na educação de jovens e adultos (EJA) e suas implicaçóes na ação docente nessa modalidade. $\mathrm{O}$ estudo se desenvolve no contexto do Grupo de Pesquisa CNPq, denominado Grupo Multidisciplinar em Educação de Jovens e Adultos (Multieja), cujos estudos e pesquisas dão-se nos âmbitos: a) da formação de professores; b) do trabalho docente; c) de cotidianos escolares; d) de práticas culturais, entre outros.

Tendo por base esses estudos ${ }^{1}$ (Capes, 2015-2020 e FAPEAL, 2017-2018) começamos por aprofundar e compreender melhor as dimensóes culturais e organizacionais, por meio de indagaçóes que têm sido levantadas nos percursos investigativos em que os professores da modalidade educação de jovens e adultos são desafiados a produzirem sentidos sobre saberes/práticas/experiências no/do exercício da docência com/para jovens, adultos e idosos analfabetos; e com aqueles que retomaram o percurso da escolarização, sujeitos de direito, praticantespensantes de conhecimento e

1. Estes estudos englobam estudantes de graduação, pós-graduação e pesquisadores. 
de aprendizagens, diante da precarização das condições de produção que lhes são oferecidas no ensino noturno em EJA.

É de salientar que, em busca no GT 18 da Anped de 2005 a 2015, não identificamos investigaçóes que envolvessem trabalho docente na EJA e suas relaçóes com culturas das organizaçôes escolares. Na pesquisa do Pibic (2015-16) surgida da investigação do Pós-doutorado acima citado - que tratou de um estudo luso-brasileiro genealógico e cartográfico da cultura organizacional escolar que apresentou de forma predominante três dimensóes cartográficas: a gestáo e organizaçáo escolar; o local e o global; e a cultura de liderança do docente -, não foram encontradas essas dimensóes em investigaçóes que envolvessem a EJA. Nessa direção, as pesquisas em desenvolvimento (Capes, 2015-20 e FAPEAL, 2017-18) constituem-se como pertinentes, no sentido de nos oferecer a oportunidade de investigar implicaçôes das culturas organizacionais e do trabalho docente na EJA. Em nossa compreensão e apoiados em Hargreaves (1998), compreender o que o professor faz e por que o faz, exige, primordialmente, compreender a cultura de trabalho da qual ele faz parte.

Assentes nesse pressuposto do pesquisador citado, assumimos como objetivo geral das pesquisas produzir conhecimento sobre a cultura organizacional escolar e o trabalho dos docentes da EJA, que atuam em escolas do município de Maceió.

Os estudos problematizam: em que medida as culturas organizacionais escolares implicam-se com o trabalho do professor de EJA? Para a coleta de dados recorremos a: observação, com registros no "diário de confidências" (Marinho, 2014); entrevistas semiestruturadas em sessóes conversas com professores e estudantes, que constituíram fontes para as análises qualitativas dos dados.

No contexto dessas investigaçôes, os loci foram três escolas do município de Maceió, tendo como critérios: a) atuarem com os anos iniciais e finais do ensino fundamental de EJA; b) contarem 
com professores efetivos; e c) se situarem em regióes geográficas distintas. Envolvem sujeitos gestores - diretor e coordenador pedagógico — , estudantes e professores.

Considerando a natureza do estudo apresentado, recorremos à análise de conteúdo (Bardin, 2008), por meio da organização de um processo de categorizaçáo semântico. Ou seja, identificaram-se categorias temáticas oriundas do sentido emergente no resultado da análise de documentos norteadores e dos dados resultantes das narrativas de professores, de estudantes e gestores.

Construímos o texto a partir de contribuiçóes teórico-epistemológicas que fundamentam a cultura como metáfora paradigmática relevante para a (re)interpretação e compreensão das açóes desenvolvidas, cotidianamente, pelos sujeitos na/da escola, articulando-se a dados empíricos recolhidos em uma das escolas dos loci de investigação.

Apoiados em autores como Teixeira (2000); Day (2001); Silva (2006); Pol et al. (2007), recorremos ao termo cultura escolar como sinônimo de cultura organizacional escolar.

\section{A cultura como metáfora paradigmática para (re)pensar e compreender processos e açóes na/da escola}

A cultura organizacional, desde os anos 1980, tem vindo a assumir-se como um conceito significativo na caracterizaçáo e elucidação de processos complexos que se desenvolvem cotidianamente nas instituições (Marinho, 2014). Para Torres (2004), esse conceito constitui-se como fundamental para a compreensão das especificidades culturais e um fator decisivo no funcionamento organizacional.

Nesse sentido, a cultura tem-se estabelecido como metáfora relevante nos estudos das/nas organizaçóes, tendo oferecido consideráveis potencialidades quando se assumem essas mesmas 
organizaçóes como culturas em movimento. A importância de incorporar essa metáfora nas análises das organizaçóes justifica-se na medida em que a metáfora cultural realça o significado simbólico de quase tudo que construímos e realizamos no cotidiano organizacional.

Nesse quadro de ideias, congregamos Aktouf (1990, p. 551), quando este sustenta que a cultura é "[...] um conjunto complexo e multidimensional de quase tudo o que faz a vida em comum nos grupos sociais", implicando no cotidiano profissional e pessoal dos sujeitos que neles se constituem.

Tal ideia parece ir também ao encontro do pressuposto de Torquato (1991), quando se refere que a cultura organizacional é constituída por múltiplas variáveis que se relacionam entre si e se moldam em um somatório de conhecimentos e vivências técnicas, administrativas, políticas, estratégicas e psicossociais, que agregam fatores humanos individuais e relacionamentos interpessoais, formais e informais.

Em outra perspectiva de análise, Morgan (1992) apresenta a cultura no domínio do simbólico, integrado por crenças, assunçóes, valores, ritos e artefatos, e assente num processo contínuo de reconstrução dinâmica. Nessa visão, é dada ênfase ao simbolismo organizacional que parte do reconhecimento de que as organizaçóes são sistemas humanos que manifestam complexos padróes de atividade cultural e não máquinas ou organismos adaptativos. $\mathrm{O}$ simbólico não se caracteriza por um reducionismo, pelo contrário, é conceptualizado por um signo que vai mais além do visível (Morgan, 1992). Segundo o autor, as organizaçôes são entidades simbólicas nas quais os seus membros produzem e interpretam metáforas, atribuem sentidos a acontecimentos, comportamentos e objetos, ou seja, os membros das organizaçóes agem na base de processos (re)interpretativos simbólicos. 
É também neste quadro simbólico que a escola como instituição, à semelhança do que acontece em outras organizaçóes sociais, vem desenvolvendo e reproduzindo culturas singulares, conexas à própria origem da escola como instituição (Silva, 2006). A este propósito, Santos Guerra (2000) advoga que a escola cria uma cultura própria que transmite normas, crenças, valores e mitos que regulam o comportamento dos seus membros. Nas palavras de Sergiovanni (2004), a cultura fornece normas que conduzem os comportamentos entre os sujeitos da instituição escolar e oferece uma estrutura para definir o que faz ou não faz sentido, ou seja, constitui-se como bússola orientadora. A cultura escolar é, assim, "[...] ativamente construída pelos seus atores, mesmo que essa construção permaneça, em grande parte, inconsciente" (Thurler, 2001, p. 90).

De posse desses pressupostos, importa reconhecer que os conteúdos e as formas da cultura que se vão forjando nos contextos organizacionais escolares têm diferentes implicaçóes no trabalho dos professores. Hargreaves (1998) sublinha isso mesmo nos estudos sobre o trabalho e a cultura dos professores, pois ao caracterizar culturas escolares e profissionais docentes em individualismo, colaboração, colegialidade artificial e balcanização, aponta como essas vivências culturais implicam nas várias dimensôes de ação dos professores.

Estamos assumindo, por um lado, a convicçáo de que o trabalho dos professores é influenciado pela cultura organizacional e profissional e, por outro lado, a enunciar a crença de que, para ser efetiva, qualquer mudança nas práticas no cotidiano escolar pressupóe mudança cultural organizacional e profissional. Caso contrário, e de forma intencional, reformas e mudanças, emergindo de investigadores, formadores ou dos movimentos pedagógicos, podem ser dissolvidas pela cultura profissional e pela cultura organizacional escolar (Thurler, 2001). Como argumenta a mesma 
autora, "[...] agir sobre a cultura é transformar os sistemas de valores e os modos de raciocínio e de cálculo dos atores" (Thurler, 2001, p. 189).

Nessa perspectiva cultural, a incerteza e a complexidade são integradas, ou seja, fazem parte de um mesmo processo, e, nesse sentido:

[...] evita as explicaçôes uni-dimensionais; em vez de lidar com a organização como um dado pertencente à ordem natural, dá realce à natureza constitutivamente simbólica (cultural) da vida organizacional. $\mathrm{O}$ paradigma cultural desafia as preocupaçóes com o controlo e a certeza, corresponderá a uma mudança epistemológica significativa: transferindo a ênfase que habitualmente recai sobre o controlar para o interpretar e conhecer (Gomes, 2000, p. 157).

Em síntese, consideramos que, assumir a cultura como metáfora paradigmática na organização escolar poderá constituir um epicentro primordial para o (re)pensar e compreender açóes dos sujeitos na/da escola que, neste caso específico, se remete aos professores da/na educação de jovens e adultos.

Reportando-nos a pressupostos teóricos da cultura organizacional escolar, subsidiamos, neste artigo, alguns "achados", que começam por surgir nas pesquisas em desenvolvimento, relativamente à cultura escolar da/na EJA.

\section{Alguns achados}

Em processos de desenvolvimento desses estudos e tendo como objetivo, como já afirmamos, produzir conhecimento para o aprofundamento teórico-epistemológico sobre as culturas organizacionais escolares e as implicaçóes no trabalho docente, alguns achados começaram a emergir nas escolas das pesquisas, o que possibilitou trazer, neste texto, três categorias surgidas das sessões conversas realizadas com professores em uma das escolas. 


\section{De um isolamento e individualismo a um "sofrimento profissional"}

A solidão profissional e individual aparece como caraterística que mais tem emergido nos discursos dos professores, quando estes se referem ao contexto e vivência cotidiana do seu trabalho, o que também aconteceu na pesquisa realizada pelo Observatório Alagoano de Leitura em EJA (Capes, 2011-14).

Situação que muitas vezes remete para um certo "sofrimento" do professor, o que Correia e Matos (2001, p. 18) argumentam, afirmando que os professores, em muitas culturas escolares, vivem um "sofrimento ético e organizacional", isto é, um sofrimento profissional que:

[...] resulta das crescentes dificuldades em instituir espaços de comunicação e linguagens profissionais que permitam a expressão pública dos dramas privados vividos da sala de aula e a promoçáo de um debate profissional legítimo sobre esses dramas privados.

Complementam os pesquisadores que:

Os professores parecem já não se reconhecerem solidariamente [...] raramente se instituem como possibilidades de promoçáo de um debate profissionalmente pertinente, mas induzem antes a produção de 'discursos deficitários' e uma multiplicação de tarefas que agravam a dissociação entre a 'vivência privada da profissão' e sua expressão pública. Contrastando com a complexidade dos problemas vividos na sala de aula que estáo frequentemente na origem de angústias e sofrimentos profissionais silenciados (Correia e Matos, 2001, p. 18).

Neste caso específico, os professores de educação de jovens e adultos denunciam essa mesma situação sustentando a sua cotidianidade em potentes espaçostempos de individualismo e isolamento 
profissional em relação a seus pares, bem como em relação à gestão. Isso ficou explícito em uma sessão conversa, ao referirem que:

Nós [professores] da noite, somos [...] cada um no seu quadrado. Não temos qualquer ligação com os colegas do diurno, nem com o que se passa na escola. Não, não temos encontros que englobam todos os professores da escola para partilha. As nossas dificuldades muitas vezes são silenciadas. Vamo-nos socorrer a quem? Eu, por exemplo, tenho muitas dificuldades com os jovens deficientes, mas que fazer? Não tenho quem me possa ajudar, não é que os colegas não queiram, mas também não podem ou não sabemos. Tantas vezes fico numa agonia sem fim. Sofrendo, sofrendo. E eu que sou das artes, sozinha, eu estou sozinha, não tenho como organizar... partilhar algo maior [...] fica tudo isolado [...]. (Sessão Conversa, 2016)

Náo tem sido destacado nas vozes dos professores a existência de espaçostempos de reflexão sobre o trabalho docente e, em particular, sobre a ação pedagógica que se constitui como base de todo esse trabalho. Essa realidade vai ao encontro do que Santos Guerra (2002) já tinha sinalizado em sua obra, bem com Hargreaves e Denins (2012), quando sustentam a premência, na organização escolar, de linhas de ação que objetivem pragmaticamente momentos para que os professores façam discussões das suas açóes contextualizadas e assumam coletivamente objetivos comuns que possam desaguar em reconfiguraçóes das referidas linhas de formas concretas e objetivas. No entanto, parece existir um tipo de nevralgia nos espaços e açóes escolares que se internalizam em pressupostos básicos culturais organizacionais (crenças, valores, concepçóes) que pouco ou nada têm contribuído para um outro cotidiano de múltiplas possibilidades de mudanças organizacionais e profissionais docentes.

É nesse mesmo sentido que Pérez-Gómez (2001) refere que o isolamento do docente, patrimonialista de sua sala de aula e 
de seu trabalho, pode ser uma das características mais difundidas e perniciosas da cultura escolar. Por múltiplas razóes históricas, a cultura do docente parece vincular a defesa de sua autonomia e independência profissional com a tendência ao isolamento, à separação, à ausência de contraste e cooperaçáo.

\section{Um “apartheid" organizacional e profissional}

Nos discursos dos professores inferimos, também, que parece proliferar uma espécie de apartheid entre dois mundos escolares: o mundo da escola diurna e o mundo da escola noturna, no caso específico da EJA, denotando em nível organizacional a existência desses dois mundos. Nos achados, ficam patentes a emergência de uma institucionalização, aparentemente silenciosa, de uma cultura de apartheid organizacional e, concomitantemente, profissional docente e discente.

No turno da noite é outra escola, é outra... Muitas vezes vimos de outra escola já cansados para trabalhar com os jovens e adultos. É complicado! Não, articulação não temos como os professores do diurno, também o trabalho é outro, à noite são jovens e adultos. De dia é uma coisa e à noite é outra. Muito diferentes, completamente diferentes. [...] (Sessão Conversa, 2016)

Nesse contexto, inferimos que é nesse apartheid que se poderá compreender o (re)criar de mitos e crenças sobre as diferenças desses dois mundos, muitas vezes infundadas, sobre os sujeitos, e que neles (mundos) se revertem em exclusóes tanto para os profissionais que neles atuam como para os estudantes que, cotidianamente, vão urdindo esses dois mundos. A exemplo, temos o turno noturno que, em muitas escolas, já se constitui de alunos excluídos do sistema dito regular e que, nessa escola noturna, 
se caracterizam por serem adolescentes e jovens, muitos deles frutos de uma exclusão de uma "pré-EJA" arquitetada em (re) engenhos, a partir de contextos de permanência do insucesso. $\mathrm{Ou}$ seja, uma "[...] permanência por vezes longa, onde muitos jovens sobrevivem nas escolas e é negado constantemente o acesso ao sucesso" (Marinho e Delgado, 2016, p. 12), o que para Santos Guerra (2002, p. 17) seria, entre outras situaçóes, uma das que reflete a construçáo do "perverso escolar", parte da engrenagem funcional cotidiana da instituição, por meio de "[...] processos instalados no modelo de ordem instituído, não contra ou à margem dele".

Segundo o mesmo autor, o "perverso" se instala quando a organização escolar experimenta a ignorância e a indignidade, vividas pela concorrência destrutiva entre alunos e a concorrência individual entre os professores. E, neste caso específico, a situação de apartheid organizacional e profissional pode reforçar esse "perverso" e, com ele, a internalização de crenças e mitos infundados, que corroem a identidade e ação profissional do professor da EJA e dos alunos dessa modalidade.

\section{Uma escola "lutadora"}

Em uma outra visão, os professores colocam suas vivências culturais embebidas em lutas de recriação e ressignificação, perante dificuldades e constrangimentos que se revelam no dia-a-dia. Isto é, assumem o direcionamento de açóes/comportamentos persistentes, que se constituem em potências de possibilidades de mudança, quando estes sustentam que:

Temos dificuldades, muitas, muitas mesmo, mas a todo o custo tentamos, tentamos que as coisas deem certo. Muitas das vezes sozinhos, mas tentando, reorientando o que não deu certo, vamos conversando 
com o colega que temos mais próximo, falamos de nossas angústias e traçamos outros caminhos, mas é difícil. Não ficamos de braços cruzados por muito tempo. Sempre lutando para que as coisas deem certo [...] por vezes ficamos desiludidos, mas [...]. (Sessão Conversa, 2016)

É importante salientar que, mesmo com todo um cenário de solidóes, isolamentos e alguns sofrimentos profissionais, a escola e seus agentes parecem congregar-se para conjunturas de uma cultura escolar lutadora. Segundo Alaíz et al (2003), uma escola lutadora é aquela em que os objetivos não são ainda muito claros, parecendo haver uma fragilidade no rumo traçado e na coordenação de esforços, quando a escola tem consciência de seus constrangimentos e aceita os desafios que lhe são propostos, não obstante tem dificuldade de abordá-los com maior sucesso, ou seja, perde muito da sua energia a tentar melhorar, e nem sempre seu esforço é bem-sucedido.

Neste cenário de características de uma cultura de escola lutadora, é pertinente a criação e o desenvolvimento de dispositivos fortalecedores de fenômenos de açóes culturais que impulsionem a mudança cultural, já que o contexto vivencial de seus agentes se constitui, em essência, potência para açôes de mudança. Segundo Duarte Gomes (2000), isto seria o despertar de uma gestão cultural para a mudança, que congregaria um ciclo de aprendizagem organizacional. Ou seja, nas palavras de Fullan e Hargreaves (2000), a escola se constituiria como uma organização aprendente.

\section{(In)conclusóes}

Com os processos e resultados desses estudos, na tentativa de produzir conhecimento para o aprofundamento teórico-epistemológico sobre culturas organizacionais escolares e profissionais docentes e, consequentemente, sobre o trabalho dos professores 
da EJA - com isso impulsionando a concretização e desenvolvimento de açóes efetivas no sentido de redefinir o lugar da EJA nas escolas - sustentamos, neste texto a cultura como metáfora paradigmática para (re)pensar e compreender a vida na/da escola.

Nesse sentido, apresentamos alguns dados de pesquisas em desenvolvimento que nos oferecem subsídios para aprofundamento dos contextos culturais-organizacionais escolares na educação de jovens e adultos, especificamente, vivenciados pelos professores dessa modalidade. Dados que colocam em evidência a constatação de culturas escolares marcadas pelo isolamento e individualismo profissional docente e a construção de apartheid organizacional e profissional, que implica no fazer e no ser docente da EJA.

Vale salientar que em um quadro cultural constrangedor, os autores e atores recriam e ressignificam, a cada momento, as dificuldades que emergem, fazendo com que possamos caracterizar, nesses contextos, a existência simultânea de culturas escolares lutadoras. Culturas essas que nos colocam em situação de potencializar possibilidades de mudança.

Em síntese, destacamos que os estudos ora em andamento, na temática emergente das culturas escolares e profissionais docentes na/da educação de jovens e adultos, podem vir a influenciar as formaçóes continuadas de professores para a modalidade EJA e, consequentemente, suas práticas pedagógicas, assentes no compromisso da construção e desenvolvimento de culturas escolares e profissionais transformadoras na educação de jovens e adultos.

\section{Referências}

ALAÍZ, Vitor et al. Autoavaliação de escolas. Pensar e praticar. Lisboa: Ed. Asa, 2013.

AKTOUF, O. "Le symbolisme et la culture d'entreprise”. In CHANLAT, J. F. (ed.). L'individu dans l'organisation. Québec: Les presses de l'université de Laval, 1990, pp. 533-88. 
BARDIN, L. Análise de conteúdo. Lisboa: Ed. 70 Ltda, 2008.

CORREIA, José Alberto e MATOS, Manuel. Solidóes e solidariedades nos quotidianos dos professores. Porto: Ediçóes Asa, 2001.

DAY, Christopher. Desenvolvimento profissional de professores. Os desafios da aprendizagem permanente. Porto: Porto Ed., 2001.

FULLAN, Michael e HARGREAVES, Andy. A escola como organização aprendente. Curitiba: Artmed, 2000.

GOMES, Duarte. Cultura organizacional - Comunicação e Identidade. Coimbra: Quarteto Editora, 2000.

HARGREAVES, Andy. Os professores em tempos de mudança: o trabalho e a cultura dos professores na idade pós-moderna. Amadora: Mc-Graw-Hill de Portugal Ltda., 1998.

e DENINS, Shirley. The fourth way: the inspiring future for educational change. California: Corwin A. Sage Company, 2012.

MARINHO, Paulo e DELGADO, Fátima. "O currículo em cursos vocacionais: o reconhecimento e construção de saberes". In XXII Colóquio da AFIRSE. Portugal, 2016.

- A avaliação da aprendizagem no ensino básico: contributos para a compreensão da sua relação com o sucesso escolar (tese). FPCEUP. Porto, 2014.

MORGAN, G. Images of organization. London: Sage, 1992.

MORGADO, José Carlos. Processos e práticas da (re)construção da autonomia curricular (tese). Universidade do Minho. Braga, 2003.

PERÉZ-GOMÉZ, A. I. A cultura escolar na sociedade neoliberal. Porto Alegre: Artmed, 2001.

POL, Milan et al. "Em busca do conceito de cultura escolar: uma contribuição para as discussôes actuais”. Revista Lusófona de Educação, n. 10, pp. 63-79, Lisboa, 2007.

SANTOS GUERRA, Miguel. Entre bastidores: o lado oculto da organização escolar. Lisboa: Ed. Asa, 2002.

SERGIOVANNI, T. O mundo da liderança. Desenvolver culturas, práticas e responsabilidade pessoal nas escolas. Porto: Ed. Asa, 2004.

SILVA, F. de C. T. "Cultura escolar: quadro conceitual e possibilidades de pesquisa”. Educar, n. 28, pp. 201-16, Curitiba, 2006. 
TEIXEIRA, Lúcia Helena G. "Cultura organizacional da escola: uma perspectiva de análise e conhecimento da unidade escolar". Revista Brasileira de Política e Administração da Educação, v. 16, n. 1, pp. 7-22, Porto Alegre, jan./jun. 2000.

THURLER, M. G. Inovar no interior da escola. Porto Alegre: Artes Médicas, 2001.

TORRES, Leonor. Cultura organizacional em contexto educativo: sedimentos culturais e processos de construção do simbólico numa escola secundária (tese). Universidade do Minho. Braga, 2004.

TORQUATO, Gaudêncio. Cultura, poder, comunicação e imagem - fundamentos da nova empresa. Sáo Paulo: Pioneira, 1991. 